\title{
ANALISIS KEBUTUHAN DAYA LISTRIK DI AKADEMI KOMUNITAS NEGERI ACEH BARAT
}

\author{
Ary Firnanda* \\ Haimi Ardiansyah \\ Akademi Komunitas Negeri Aceh Barat
}

\begin{abstract}
Analysis of electric power consumption at Community College of West Aceh is highly indispensable to be done in order to get information whether the existing electric power merits the requirements or need to be upgrated. This study aims to analyze the demand of electric power at Community College of West Aceh. Literature study and field observation are selected as data collection methods. Field observation is carried out by observing the electrical power requirements of each equipment that uses direct electric power as well as LocalCooling application. Based on the result, it is found that metal welding laboratory consumes more power than other rooms which is $31.26 \%$ over total electric power. Currently, the electric power needed by Community College of West Aceh is 67,740 Watts whereby total available electric power is 88,218.5 Watts. The result shows that the existing electric power at the Community College of West Aceh is in accordance with the needs. However, it is important to concern on the electric distribution so that it is ensured each room acquires the electric power as needed.
\end{abstract}

Keywords:

Electric Power; Electric Power Consumption; Electric Power Distribution.

\begin{abstract}
Abstrak
Analisa terhadap daya listrik di Akademi Komunitas Negeri Aceh Barat sangat penting untuk dilakukan agar mendapatkan informasi apakah daya listrik yang tersedia selama ini sudah sesuai dengan kebutuhan atau belum sehingga perlu dilakukan penambahan daya listrik. Penelitian ini bertujuan untuk melakukan analisa terhadap kebutuhan daya listrik dan daya listrik yang tersedia di Akademi Komunitas Negeri Aceh Barat. Penelitian ini menggunakan metode penelitian studi literatur dan observasi lapangan. Observasi lapangan dilakukan dengan melihat kebutuhan daya listrik pada setiap peralatan yang membutuhkan daya listrik langsung dan yang menggunakan aplikasi LocalCooling. Laboratorium Teknologi Pengelasan Logam merupakan ruangan yang membutuhkan daya listrik lebih besar dibandingkan ruangan lainnya dimana ruangan Laboratorium Teknologi Pengelasan Logam membutuhkan daya listrik sebesar 31,26\% dari total kebutuhan daya listrik di Akademi Komunitas Negeri Aceh Barat. Saat ini daya listrik yang dibutuhkan oleh Akademi Komunitas Negeri Aceh Barat sebesar 67.740 Watt dengan total daya listrik yang tersedia sebesar 88.218,5 Watt. Hasil penelitian menunjukkan bahwa daya listrik yang tersedia di Akademi Komunitas Negeri Aceh Barat sudah sesuai kebutuhan. Akan tetapi, distribusi daya listrik perlu diperhatikan agar setiap ruangan mendapatkan daya listrik sesuai kebutuhan.
\end{abstract}

Kata Kunci:

Daya Listrik; Kebutuhan Daya Listrik; Distribusi Daya Listrik.

DOI: $10.38038 /$ vocatech.v2i1.41

Received: 31 Agustus 2020 ; Accepted: 06 October 2020 ; Published: 15 October 2020

\section{${ }^{*}$ Corresponding author:}

Ary Firnanda, Program Studi Instalasi dan Pemeliharaan Jaringan Listrik, Akademi Komunitas Negeri Aceh Barat, Komplek STTU Alue Peunyareng Meureubo, Meulaboh 23681.

Email: aryfirnanda@aknacehbarat.ac.id

Citation in APA Style: Firnanda, A., \& Ardiansyah, H. (2020). Analisis Kebutuhan Daya Listrik di Akademi Komunitas Negeri Aceh Barat. VOCATECH: Vocational Education and Technology Journal Vol. 2, 1 (2020), 5966. 


\section{PENDAHULUAN}

Akademi Komunitas Negeri Aceh Barat merupakan perguruan tinggi vokasi dimana kurikulum pendidikan vokasi lebih memberikan persentase proses pembelajaran praktikum lebih besar dibandingkan teori. Proses pembelajaran praktikum tentunya menggunakan peralatanperalatan yang membutuhkan daya listrik yang tidak sedikit. Analisa terhadap daya listrik di Akademi Komunitas Negeri Aceh Barat sangat penting untuk dilakukan agar mendapatkan informasi apakah daya listrik yang tersedia selama ini sudah sesuai dengan kebutuhan atau belum. Penelitian ini bertujuan untuk melakukan analisa terhadap kebutuhan daya listrik dan daya listrik yang tersedia di Akademi Komunitas Negeri Aceh Barat.

Sehingga, penelitian ini akan mendapatkan data berupa berapa watt daya yang dibutuhkan dan berapa watt daya listrik yang tersedia. Dengan demikian, apabila kebutuhan daya listrik lebih besar dari daya listrik yang tersedia maka diperlukan penambahan daya listrik. Kemudian, jika daya listrik yang tersedia lebih besar dari kebutuhan daya listrik maka dapat dipahami bahwa kebutuhan daya listrik sudah sesuai dengan kebutuhan. (Wahid, 2014), melakukan penelitian untuk melakukan analisis kapasitas dan kebutuhan daya listrik untuk menghemat penggunaan energi listrik di Fakultas Teknik Universitas Tanjungpura. (Wahid, 2014), menggunakan metode studi literatur dan observasi. Hasil penelitian dari (Wahid, 2014), menunjukkan bahwa terdapat perbedaan daya yang dianalisis secara teoritis dengan daya yang dikonsumsi selama ini dimana hal tersebut kemungkinan karena pada daya yang dikonsumsi selama ini terdapat perhitungan beban pada daya yang tidak dihitung secara teoritis sehingga perlu melakukan beberapa langkah penghematan untuk menurunkan penggunaan energi listrik di Fakultas Teknik Universitas Tanjungpura. (Meliala \& Situmeang, 2015), melakukan penelitian untuk melakukan analisis sistem kelistrikan di Universitas Lancang Kuning Pekanbaru dengan menggunakan Electric Transient and Analysis Program (ETAP). (Meliala \& Situmeang, 2015), menggunakan teorema aliran daya dan software Electric Transient and Analisys (ETAP) versi ETAP 7.0 dimana digunakan untuk mempelajari profil tegangan dan daya di Universitas Lancang Kuning. Hasil penelitian yang telah dilakukan oleh (Meliala \& Situmeang, 2015), menunjukkan bahwa sistem kondisi eksisting besar arus pada panel utama yang berada di ruangan
Genset Unilak sebesar 211 A, tegangan 378 V line-to-line dan daya $142 \mathrm{~kW}$. (Notosudjono, 2016), melakukan penelitian untuk menganalisa kebutuhan daya listrik di gedung perkuliahan 10 lantai Universitas Pakuan Bogor. (Notosudjono, 2016), menunjukkan bahwa beban-beban listrik, seperti beban penerangan, beban tenaga, dan beban motor-motor listrik membutuhkan daya listrik yang cukup besar. Dimana untuk memenuhi kebutuhan daya tersebut mengandalkan suplai daya listrik dari PLN dan generator set sebagai sumber daya listrik cadangan. (Fadillah \& Sukma, 2015), melakukan penelitian untuk menganalisis prakiraan kebutuhan energi listrik tahun 20152024 wilayah PLN Kota Pekanbaru dengan metode gabungan. (Fadillah \& Sukma, 2015), menggunakan metode analisis, metode ekonomi, dan metode trend. Hasil penelitian dari (Fadillah \& Sukma, 2015), menunjukkan bahwa terjadi peningkatan kebutuhan daya listrik setiap tahun. (Nigara et al., 2015), melakukan penelitian untuk menganalisis daya sistem tenaga listrik pada bagian texturizing di PT. Asia Pasific Fibers Tbk Kendal menggunakan software ETAP Power Station 4.0. (Nigara et al., 2015), menghitung daya aktif dan daya reaktif, pembebanan pada transformator, pembebanan pada saluran atau penghantar, nilai rugi daya (Losses), jatuh tegangan sistem, dan aliran daya pada jaringan sistem tenaga listrik terpasang. Hasil penelitian yang telah dilakukan oleh (Nigara et al., 2015), menunjukkan bahwa sistem jaringan listrik sudah baik. Kemudian, selisih rugi daya aktif dan rugi daya reaktif pada Bus Beban 4 terlalu besar. Sedangkan jatuh tegangan masih memenuhi standar menurut hasil Text Report pada ETAP. (Nur \& Cholilurrahman, 2014), melakukan penelitian untuk menganalisa keandalan sistem kelistrikan 3 Fase pada Hotel Bisanta Bidakara Surabaya. (Nur \& Cholilurrahman, 2014), menunjukkan bahwa indeks keandalan masih perlu diperbaiki. (Candra \& Setyaningsih, 2012), melakukan penelitian untuk menganalisis efisiensi konsumsi daya listrik dan biaya operasional lampu $T L-L E D$ terhadap lampu TL-T8. (Candra \& Setyaningsih, 2012), melakukan pengukuran dengan menggunakan parameter iluminansi dan daya beban listrik terpasang dimana hasil penelitian menunjukkan bahwa konsumsi daya lampu $T L-L E D$ lebih efisien dibandingkan dengan lampu TL-T8. (Maharmi \& Kardova, 2018), melakukan penelitian untuk menganalisa konsumsi energi listrik rumah dengan kendali otomatis. Hasil penelitian dari (Maharmi \& Kardova, 2018), 
menunjukkan bahwa pemakaian alat kendali otomatis untuk mengontrol lampu penerangan rumah lebih hemat energi dibandingkan dengan sistem manual. (Faridha \& Saputra, 2016), melakukan penelitian untuk menganalisa pemakaian daya lampu $L E D$ pada rumah tipe 36 . (Faridha \& Saputra, 2016), menggunakan jenis penelitian kuantitatif dimana pada rumah tipe 36 mengkonsumsi daya 23,04 KWh perbulan. (Ardianto et al., 2017), melakukan penelitian tentang peluang penghematan energi pada gedung Fakultas Teknik Universitas Muhammadiyah Palembang. (Ardianto et al., 2017), menggunakan nilai Intensitas Konsumsi Energi (IKE) sebagai tolak ukur menghitung potensi penghematan energi. Hasil penelitian yang telah dilakukan oleh (Ardianto et al., 2017), menunjukkan bahwa penggunaan beban terpakai selama 9 jam kerja adalah sebesar 349.603 Watt. (Setiawan et al., 2000), melakukan penelitian untuk menganalisa teknis dan perencanaan pada panel utama tegangan rendah di Harco Mangga Besar. (Setiawan et al., 2000), menunjukkan bahwa trafo mampu mengatasi pertumbuhan beban dengan mempertimbangkan karakteristik beban. (Mangantar, 2014), melakukan penelitian untuk menganalisa efisiensi konsumsi energi listrik pada kapal motor penumpang Nusa Mulia. (Mangantar, 2014), menunjukkan bahwa besarnya pemakaian energi listrik dipengaruhi oleh jenis beban yang dipakai. (Tambunan et al., 2015), melakukan penelitian untuk menganalisis pengaruh jenis beban listrik terhadap kinerja pemutus daya listrik di gedung cyber Jakarta. (Tambunan et al., 2015), menunjukkan bahwa distorsi gelombang harmonic dapat menyebabkan naiknya arus dan tegangan pada kawat netral. (Rahman \& Nanggalo, 2015), melakukan penelitian tentang prakiraan dan analisa kebutuhan energi listrik Provinsi Sumatera Barat hingga tahun 2024 dengan metode analisis regresi linear berganda. (Rahman \& Nanggalo, 2015), memanfaatkan data-data historis konsumsi energi listrik pada masa lampau, menggunakan metode regresi linear berganda serta software SPSS 15.0 untuk melakukan prakiraan kebutuhan energi listrik. Hasil penelitian yang telah dilakukan oleh (Rahman \& Nanggalo, 2015), menunjukkan bahwa kebutuhan energi listrik cenderung meningkat dari tahun ke tahun dimana rata-rata peningkatan per tahun $3.59 \%$.

(Saifuddin et al., 2018), melakukan penelitian untuk menganalisa kebutuhan daya listrik terpasang pada gedung Kantor Bupati Kabupaten Halmahera Barat. (Saifuddin et al., 2018), menunjukkan bahwa faktor kebutuhan adalah perbandingan antara kebutuhan maksimum (beban puncak) terhadap total daya tersambung. (Albahar \& Maulana, 2019), melakukan penelitian untuk menganalisa kebutuhan daya listrik di gedung Dinas Wali Kota Bekasi. Hasil penelitian yang telah dilakukan oleh (Albahar \& Maulana, 2019), menunjukkan bahwa untuk memperbaiki kualitas daya listrik terpasang kapasitor bank dengan kapasitas $600 \mathrm{kVAr}$ untuk memperbaiki faktor daya. (Djohar \& Musaruddin, 2017), melakukan penelitian untuk menganalisis kebutuhan dan penyediaan energi listrik di Kabupaten Konawe Kepulauan tahun 2017-2036 dengan menggunakan perangkat lunak Leap. Hasil penelitian yang telah dilakukan oleh (Djohar \& Musaruddin, 2017), menunjukkan bahwa pertumbuhan tingkat aktivitas energi sekitar 3,4\% tiap tahun. (Faridah et al., 2018), melakukan penelitian untuk menganalisis penghematan daya listrik di PT. Daikin Air Conditioning Makassar. (Faridah et al., 2018), menunjukkan bahwa $A C$ merupakan peralatan yang banyak mengkonsumsi energi listrik dimana menggunakan hampir sekitar $60 \%$ energi listrik pada suatu bangunan dimana hal ini merupakan suatu pemborosan energi. Penelitianpenelitian yang telah dilakukan tersebut menujukkan bahwa penelitian sejenis telah dilakukan pada beberapa tempat. Penelitian ini dilakukan di Akademi Komunitas Negeri Aceh Barat. Selanjutnya, penelitian ini akan menghasilkan analisis terhadap kebutuhan daya listrik dan daya listrik yang terpasang saat ini di Akademi Komunitas Negeri Aceh Barat serta distribusi kebutuhan daya listrik di Akademi Komunitas Negeri Aceh Barat.

\section{STUDI PUSTAKA}

\section{A. Energi Listrik}

(Wahid, 2014), mendefinisikan bahwa energi merupakan kemampuan untuk melakukan kerja dimana dalam ilmu fisika disebut kemampuan melakukan usaha serta energi tidak dapat diciptakan maupun dimusnahkan. Kemudian, (Wahid, 2014) menambahkan bahwa energi hanya dapat berubah bentuk seperti energi mekanik berubah bentuk menjadi energi listrik serta energi listrik ini dapat digunakan dengan maksimal dimana contoh kegunaan energi listrik seperti penerangan, pemanas, motor-motor listrik dan lain-lain. Apabila daya diukur dalam watt jam, maka (Wahid, 2014) :

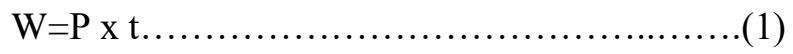


Dengan:

$\mathrm{P} \quad=$ daya dalam watt

$\mathrm{T}=$ Waktu dalam jam

$\mathrm{W}=$ Energi dalam watt jam

Watt jam (wathour $=\mathrm{Wh}$ ) merupakan energi yang dikeluarkan jika 1 watt digunakan selama 1 jam.

\section{B. Sistem Tenaga Listrik}

(Wahid, 2014), menyebutkan bahwa keperluan penyediaan tenaga listrik bagi para pelanggan, memerlukan berbagai peralatan listrik untuk membentuk suatu sistem tenaga listrik dimana kebutuhan tenaga listrik dari pelanggan selalu bertambah setiap waktu sehingga sistem tenaga listrik perlu terus ditingkatkan untuk memenuhi kebutuhan listrik. Kemudian, diperlukan analisa dan evaluasi yaitu (Wahid, 2014) :

a. Bilamana, beberapa besar dan dimana perlu dibangun pusat listrik baru, GI baru serta saluran transmisi baru.

b. Menambah unit pembangkit dan menambah transformator dan lain-lain

c. Bilamana dan dimana saja perlu penggantian PMT dengan yang lebih besar sebagai konsekuensi dari butir a dan $b$.

\section{Daya Listrik}

(Notosudjono, 2016), mendefinisikan daya listrik merupakan jumlah energi yang diserap atau dihasilkan pada sebuah rangkaian sehingga sumber energy akan menghasilkan daya listrik dan beban yang terhubung akan menyerap daya listrik tersebut dimana daya listrik merupakan tingkat konsumsi daya listrik pada sebuah rangkaian listrik seperti contoh lampu pijar dan Heater (Pemanas). Rumus yang digunakan adalah (Notosudjono, 2016) :

$\mathrm{P}=\mathrm{V}$ x I. .

Dimana:

$\mathrm{P}=$ daya listrik $(\mathrm{W})$

$\mathrm{V}=$ tegangan listrik $(\mathrm{V})$

$\mathrm{I}=\operatorname{arus} \operatorname{listrik}(\mathrm{I})$

\section{Segitiga Daya}

(Notosudjono, 2016), mendefinisikan segitiga daya merupakan hubungan antara daya nyata, daya semu dan daya reaktif yang digambarkan sebagai berikut :

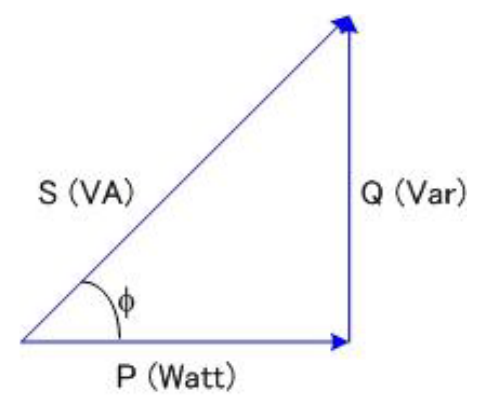

Gambar 1. Segitiga hubung antara daya nyata, daya semu dan daya reaktif

\section{E. Kebutuhan Maksimum}

(Notosudjono, 2016), menyebutkan bahwa beban puncak didefinisikan sebagai beban terbesar pada suatu periode seperti sehari, sebulan, maupun setahun. Periode harian digambarkan sebagai berikut :

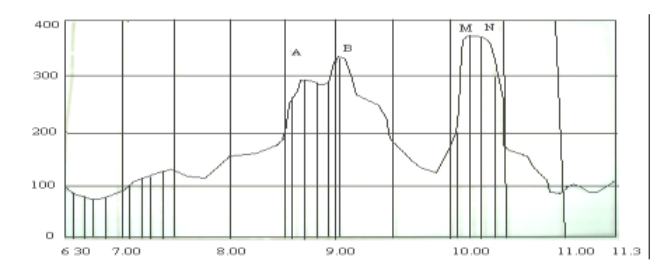

Gambar 2. Cara menentukan besaran deman

\section{F. Faktor Kebutuhan (Demand)}

(Notosudjono, 2016), menyebutkan faktor kebutuhan merupakan perbandingan antara kebutuhan maksimum terhadap total daya tersambung dimana rumus yang digunakan adalah sebagai berikut :

Faktor Kebutuhan $(\mathrm{FK})=$

Kebutuhan maksimum

Jumlah daya tersambung

\section{G. Faktor Diversitas (Fd)}

(Notosudjono, 2016), menyebutkan faktor diversitas adalah perbandingan antara jumlah beban puncak dari pelanggan pada suatu kelompok dengan beban puncak dimana secara matematis faktor diversitas (Fd) adalah sebagai berikut :

Faktor diversitas $(\mathrm{FD})=$

$\frac{D 1+D 2+D 3+\ldots+D n}{D k}$.

Atau :

$F d=\frac{\sum_{i}^{n}=1 D i}{D k}$.

Dimana:

Faktor diversitas $=\mathrm{Fd}$ ini, nilainya lebih besar dari satu 
$\mathrm{Dk}=\mathrm{D} 1+2+3 \ldots \ldots+\mathrm{n}=\begin{aligned} & \text { Beban puncak dari } \mathrm{n} \\ & \text { kelompok beban }\end{aligned}$

D1= Beban puncak (kebutuhan maks) dari masing beban i, yang terjadi tidak pada waktu bersamaan.

\section{H. Faktor Kebersamaan}

(Notosudjono, 2016), menyebutkan faktor kebersamaan (waktu) dalam perbandingan beban puncak (kebutuhan maksimum) dari suatu kelompok pelanggan (beban) dan beban puncak dari masing-masing pelanggan dari kelompok tersebut sehingga faktor kebersamaan Fc adalah sebagai berikut :

$$
\begin{aligned}
& F C= \\
& \frac{D k}{D 1+D 2+D 3+\cdots+D n}
\end{aligned}
$$

Dari definisi diatas dapat diketahui :

$F C=$

$\frac{1}{F d}$.

Dari persamaan (2.2) faktor kebutuhan (Fk) adalah :

Faktor Kebutuhan $(F K)=\frac{\text { Kebutuhan maksimum }}{\text { Jumlah daya tersambung }}$

Atau :

Kebutuhan maksimum $=$ jumlah daya tersambung $x$ Fk...(2.9)

Disubtitusikan Persamaan (2.7) ke dalam persamaan (2.5), maka faktor diversitas dapat juga dinyatakan sebagai berikut :

$F d=$

$\frac{\sum_{i=1}^{n} T D T i x F d d i}{D k}$

Dimana : $T D T_{i}$ adalah jumlah daya tersambung dari suatu kelompok atau beban i. $F d d_{i}$ adalah kebutuhan dari suatu kelompok atau beban I.

\section{METODE}

\section{A. Alur Pelaksanaan Penelitian}

Penelitian ini dilaksanakan dengan menggunakan metode studi literatur dan observasi lapangan. Objek yang akan diteliti pada penelitian ini adalah daya listrik. Dimana, pertama akan mendata kebutuhan daya listrik pada setiap ruangan, kedua melakukan analisa kebutuhan daya listrik pada setiap ruangan tersebut, ketiga setelah mendapatkan data dari hasil analisa tersebut maka data kebutuhan daya listrik akan dibandingkan dengan daya listrik yang tersedia. Apabila besaran kebutuhan daya listrik lebih besar dari daya listrik yang tersedia selama ini maka perlu dilakukan penambahan daya listrik. Sedangkan, jika kebutuhan daya listrik lebih kecil dari daya listrik yang tersedia maka tidak perlu dilakukan penambahan daya listrik. Alur penelitian yang dilakukan pada penelitian ini ditunjukkan pada Gambar 3. Flow chart alur penelitian.

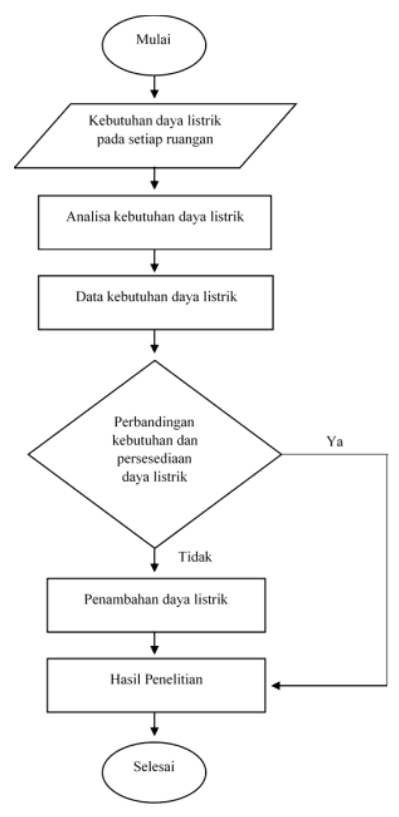

Gambar 3. Flow chart alur penelitian

\section{B. Alat dan Materi}

Penelitian untuk mendapatkan informasi mengenai berapa kebutuhan daya listrik pada setiap peralatan dilakukan dengan 2 cara yaitu menggunakan aplikasi dan pengecekan langsung pada peralatan tersebut. Pada komputer dan laptop menggunakan aplikasi LocalCooling dan pada peralatan lain seperti peralatan alat-alat praktikum, lampu, kipas angin, dan $A C$ melakukan pengecekan langsung pada peralatan tersebut.

\section{Tempat Penelitian}

Penelitian ini dilaksanakan di Akademi Komunitas Negeri Aceh Barat. Adapun denah ruangan di Akademi Komunitas Negeri Aceh Barat ditunjukkan pada Gambar 4. Denah ruangan Akademi Komunitas Negeri Aceh Barat. 


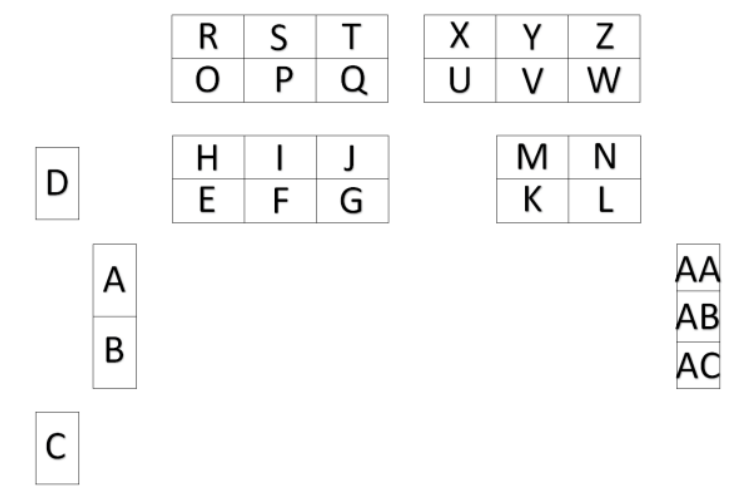

Keterangan :

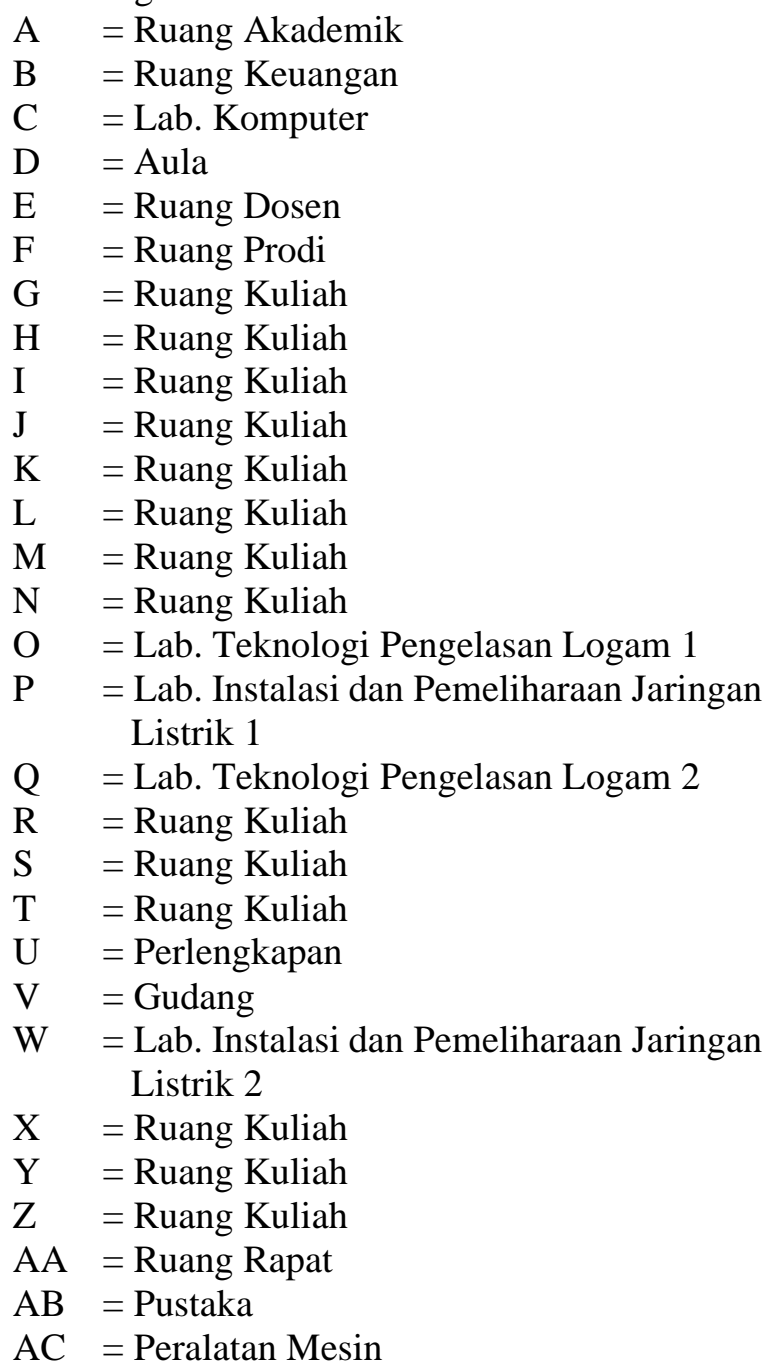

Gambar 4. Denah ruangan Akademi Komunitas Negeri Aceh Barat

\section{HASIL DAN PEMBAHASAN}

Berdasarkan data dari hasil penelitian yang ditunjukkan pada Tabel 1. Kebutuhan daya listrik sebagai berikut :
Tabel 1. Kebutuhan daya listrik

\begin{tabular}{|c|c|c|c|}
\hline No. & Nama Ruangan & $\begin{array}{c}\text { Kebutuhan } \\
\text { Daya Listrik } \\
\text { (Watt) }\end{array}$ & Keterangan \\
\hline 1 & Akademik & 7.023 & \\
\hline 2 & Keuangan & 2.039 & \\
\hline 3 & Dosen & 2.718 & \\
\hline 4 & Prodi & 710 & \\
\hline 5 & Rapat & 1.677 & \\
\hline 6 & Pustaka & 1.759 & \\
\hline 7 & $\begin{array}{l}\text { Lab. Teknologi } \\
\text { Pengelasan Logam } \\
1\end{array}$ & 21.177 & \\
\hline 8 & $\begin{array}{l}\text { Lab. Teknologi } \\
\text { Pengelasan Logam } \\
2\end{array}$ & 167 & \\
\hline 9 & $\begin{array}{l}\text { Lab. Instalasi dan } \\
\text { Pemeliharaan } \\
\text { Jaringan Listrik } 1\end{array}$ & 167 & \\
\hline 10 & $\begin{array}{l}\text { Lab. Instalasi dan } \\
\text { Pemeliharaan } \\
\text { Jaringan Listrik } 2\end{array}$ & 1.759 & \\
\hline 11 & Perlengkapan & 1.841 & \\
\hline 12 & Gudang & 167 & \\
\hline 13 & Kuliah & 2.338 & 14 Ruang \\
\hline 14 & Aula & 18.876 & \\
\hline 15 & Peralatan Mesin & 1.677 & \\
\hline 16 & Lab. Komputer & 3.645 & \\
\hline
\end{tabular}

Kebutuhan daya listrik menunjukkan bahwa Laboratorium Teknologi Pengelasan Logam 1 merupakan ruangan yang membutuhkan daya listrik yang paling besar yaitu 21.177 Watt. Hal ini dikarenakan pada Laboratorium Teknologi Pengelasan Logam 1 terdapat beberapa peralatan mesin yang membutuhkan daya listrik yang besar ketika mesin tersebut beroperasi. Kemudian, Laboratorium Teknologi Pengelasan Logam 2, Laboratorium Instalasi dan Pemeliharaan Jaringan Listrik 1, dan Gudang merupakan ruangan yang membutuhkan daya listrik yang paling sedikit.

Laboratorium Teknologi Pengelasan Logam 2 peralatan yang ada tidak menggunakan arus listrik dimana kegiatan pada laboratorium ini adalah kerja bangku dimana peralatan yang membutuhkan daya listrik yaitu lampu dan kipas angin. Laboratorium Instalasi dan Pemeliharaan Jaringan Listrik 1 juga demikian dimana kegiatan pada laboratorium ini adalah terbatas pada merakit peralatan listrik. Ruang Kuliah membutuhkan daya listrik sebesar 2.338 Watt dikarenakan terdapat 14 ruang kuliah dimana 1 ruang kuliah hanya membutuhkan daya listrik sebesar 167 Watt. Hasil penelitian juga menunjukkan bahwa ada beberapa ruangan yang kebutuhan daya listrik sama yaitu 
ruang rapat dan ruang peralatan mesin dengan kebutuhan daya listrik sebesar 1.677 Watt. Selanjutnya, ruang pustaka dan ruang Laboratorium Instalasi dan Pemeliharaan Jaringan Listrik 2 dengan kebutuhan daya listrik sebesar 1.759 Watt. Kemudian, ruang yang kebutuhan daya listrik yang sama ditunjukkan pada ruang Laboratorium Teknologi Pengelasan Logam 2, Laboratorium Instalasi dan Pemeliharaan Jaringan Listrik 1, Gudang, dan 1 ruang kuliah sebesar 167 Watt. Secara keseluruhan kebutuhan daya listrik pada semua ruangan di Akademi Komunitas Negeri Aceh Barat adalah sebesar 67.740 Watt. Persentase kebutuhan daya listrik pada setiap ruangan di Akademi Komunitas Negeri Aceh Barat ditunjukkan pada Gambar 5. Persentase kebutuhan daya listrik.

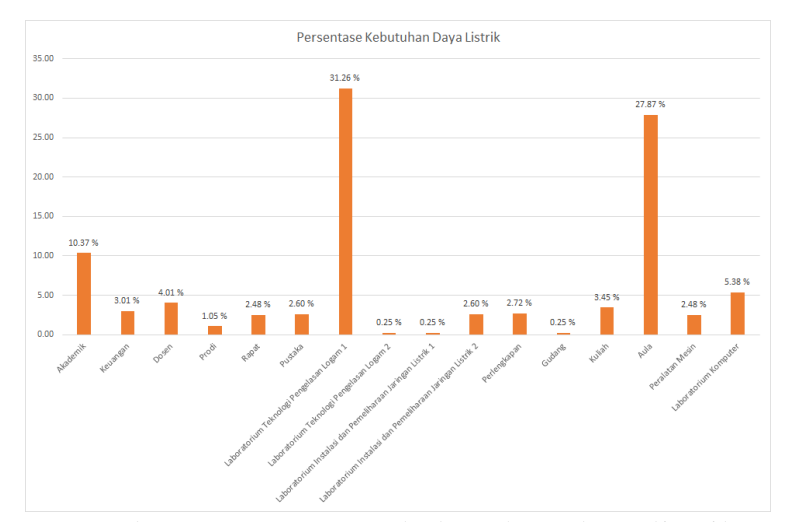

Gambar 5. Persentase kebutuhan daya listrik

Berdasarkan grafik yang ditunjukkan pada Gambar 5. Persentase kebutuhan daya listrik menunjukkan bahwa Laboratorium Teknologi Pengelasan Logam 1 membutuhkan daya listrik $31.26 \%$ dari 67.740 Watt kebutuhan daya listrik di Akademi Komunitas Negeri Aceh Barat. Selanjutnya, aula membutuhkan daya listrik 27.87 $\%$ dari kebutuhan daya listrik di Akademi Komunitas Negeri Aceh Barat. Dengan demikian dapat dipahami bahwa 2 ruangan tersebut merupakan ruangan dengan kebutuhan daya listrik yang lebih besar dibandingkan ruangan lain dimana 2 ruangan tersebut membutuhkan daya listrik diatas $20 \%$ dari kebutuhan daya listrik di Akademi Komunitas Negeri Aceh Barat. Akademi Komunitas Negeri Aceh Barat terinstalasi listrik 3 phase dengan arus $50 \mathrm{~A}$ dengan daya 83.818,5 Watt dan listrik 1 phase dengan arus 20 A dengan daya 4.400 Watt sehingga keseluruhan memiliki daya sebesar 88.218,5 Watt. Perbandingan Antara kebutuhan daya listrik dengan daya listrik yang tersedia di Akademi Komunitas Negeri Aceh Barat ditunjukkan pada Gambar 6. Perbandingan kebutuhan dan ketersediaan daya Listrik.

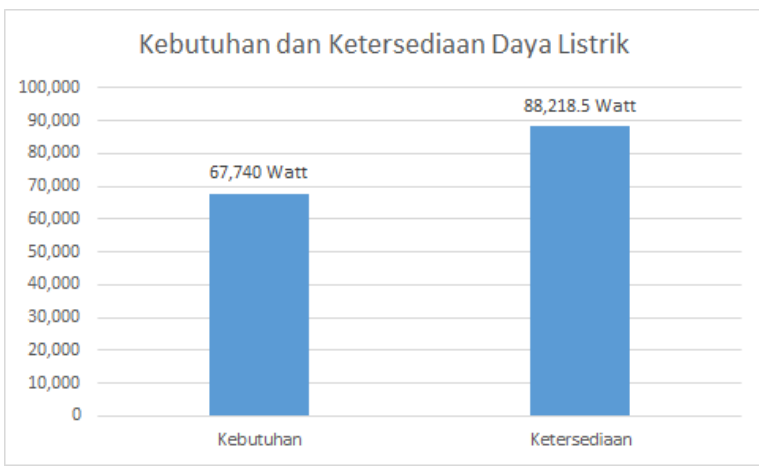

Gambar 6. Perbandingan kebutuhan dan ketersediaan daya listrik

Berdasarkan Gambar 6. Perbandingan kebutuhan dan ketersediaan daya listrik tersebut menunjukkan bahwa kebutuhan daya listrik lebih kecil dibandingkan dengan daya listrik yang tersedia.

\section{KESIMPULAN}

\section{A. Kesimpulan}

Berdasarkan hasil penelitian dapat disimpulkan bahwa kebutuhan daya listrik lebih kecil dibandingkan ketersediaan daya listrik sehingga tidak perlu dilakukan penambahan daya listrik. Distribusi daya listrik perlu dibenahi agar setiap ruangan mendapatkan daya listrik sesuai kebutuhan.

\section{B. Saran}

Distribusi daya listrik perlu dibenahi agar setiap ruangan mendapatkan daya listrik sesuai kebutuhan.

\section{REFERENSI}

Wahid, A. (2014). Analisis Kapasitas dan Kebutuhan Daya Listrik untuk Menghemat Penggunaan Energi Listrik di Fakultas Teknik Universitas Tanjungpura.

Meliala, D., \& Situmeang, U. (2015). Analisis Sistem Kelistrikan di Universitas Lancang Kuning Pekanbaru dengan Menggunakan Electric Transient and Analysis Program ( ETAP ). 178-187.

Notosudjono, D. (2016). Analisa Kebutuhan Daya Listrik di Gedung Perkuliahan 10 Lantai Universitas Pakuan Bogor.

Fadillah, M. B., \& Sukma, D. Y. (2015). Analisis Prakiraan Kebutuhan Energi Listrik Tahun 
2015-2024 Wilayah PLN Kota Pekanbaru dengan Metode Gabungan. 2(2), 1-10.

Nigara, A. G., \& Primadiyono, Y. (2015). Analisis Aliran Daya Sistem Tenaga Listrik pada Bagian Texturizing di PT. Asia Pasific Fibers Tbk Kendal Menggunakan Software ETAP Power Station 4 . 0. 7(1), $2-5$.

Nur, R., \& Cholilurrahman, R. A. (2014). Analisa Keandalan Sistem Kelistrikan 3 Fase pada Hotel Bisanta Bidakara Surabaya. Jurnal Emitor Vol.17 No. 01 ISSN 1411-8890. 17(01), 1-5.

Candra, H., \& Setyaningsih, E. (2012). Analisis Efisiensi Konsumsi Daya Listrik dan Biaya Operasional Lampu TL-LED Terhadap Lampu TL-T8. 8, 186-193.

Maharmi, B., \& Kardova, T. (2018). Analisa Konsumsi Energi Listrik Rumah dengan Kendali Otomatis. 2(2), 37-43.

Faridha, M., \& Saputra, M. D. Y. (2016). Jurnal Teknologi Elektro , Universitas Mercu Buana ISSN : 2086-9479 Analisa Pemakaian Daya Lampu LED pada Rumah Tipe 36 Jurnal Teknologi Elektro , Universitas Mercu Buana ISSN : 20869479. 7(3), 193-198.

Ardianto, F., Hurairah, M., Azis, I. (2017). Peluang Penghematan Energi pada Gedung Fakultas Teknik Universitas Muhammadiyah Palembang. Page 71 . 1(2), 71-78.

Setiawan, I., Sikki, M. I. (2000). Analisa Teknis dan Perencanaan pada Panel Utama Tegangan Rendah di Harco Mangga Besar. 5(1), 63-74.

Mangantar, D. (2014). Analisa Efisiensi Konsumsi Energi Listrik pada Kapal Motor Penumpang Nusa Mulia. 3(1), 54-60.

Tambunan, J. M. (2015). Analisis Pengaruh Jenis Beban Listrik terhadap Kinerja Pemutus Daya Listrik di Gedung Cyber Jakarta.

Rahman, A., \& Nanggalo, K. (2015). Prakiraan dan Analisa Kebutuhan Energi Listrik Provinsi Sumatera Barat hingga Tahun 2024 dengan Metode Analisis Regresi Linear Berganda. 4(2).

Saifuddin, M. A. H., Djufri, I. A., Rahman, M. N. (2018). Analisa Kebutuhan Daya Listrik Terpasang pada Gedung Kantor Bupati Kabupaten Halmahera Barat. 05(1), 4957.

Albahar, A. K., \& Maulana, D. (2019). Analisa Kebutuhan Daya Listrik di Gedung Dinas Wali Kota Bekasi. 104-109.
Djohar, A., \& Musaruddin, M. (2017). Analisis Kebutuhan dan Penyediaan Energi Listrik di Kabupaten Konawe Kepulauan Tahun 2017-2036 dengan Menggunakan Perangkat Lunak Leap. 293-298.

Faridah (2018). Analisis Penghematan Daya Listrik di PT. Daikin Air Conditioning Makassar. 16(2), 85-92.

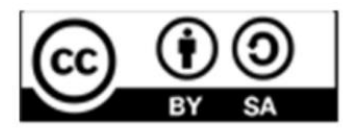

Copyright (C) 2020

Vocatech: Vocational Education and Technology Journal This works is licensed under a Creative Common Attribution-ShareAlike 4.0 